\title{
Distribuição de Biomphalaria (Gastropoda, Planorbidae) nos Estados do Rio Grande do Sul e Santa Catarina, Brasil
}

\section{The distribuition of Biomphalaria (Gastropoda, Planorbidae) in Rio Grande do Sul and Santa Catarina States, Brazil}

\author{
Horacio Manuel Santana Teles*, Paulo Antônio Cypriano Pereira**, Lucia Maria Zani Richinitti **
}

\begin{abstract}
TELES, H.M.S. et al. Distribuição de Biomphalaria (Gastropoda, Planorbidae) nos Estados do Rio Grande do Sul e Santa Catarina, Brasil. Rev. Saúde públ., S. Paulo, 25: 350-2 , 1991. É apresentada análise dos conhecimentos sobre a biogeografia das espécies de Biomphalaria transmissoras de Schistosoma mansoni, abrangendo os Estados do Rio Grande do Sul e Santa Catarina (Brasil) bem como o relato do encontro de novas localidades colonizadas pelos planorbídeos. Comenta possibilidade da expansão da esquistossomose ao sul do Brasil.
\end{abstract}

Descritores: Biomphalaria. Distribuição espacial, Esquistossomose mansônica, epidemiologia.

\section{Introdução}

Os registros de ocorrência dos planorbídeos do gênero Biomphalaria são muito importantes porque o grupo reúne as espécies de caramujos que atuam como hospedeiros intermediários de Schistossoma mansoni. Com o número significativo de registros, melhoram os conhecimentos a respeito das áreas colonizadas, essenciais no planejamento das atividades de controle e vigilância epidemiológica da esquistossomose. Todavia, os detalhes que permitem a compreensão adequada da biogeografia dos caramujos nos Estados do Rio Grande do Sul (RS) e Santa Catarina (SC), ainda estão aquém do solicitado para a realização de uma análise definitiva da situação instalada. Sendo assim, procurando contribuir para a melhoria desses conhecimentos, são apresentados novos encontros de Biomphalaria, seguidos de um apanhado das circunstâncias que envolvem os conhecimentos sobre a distribuição das espécies hospedeiras intermediárias da endemia. Também é dada ênfase para a possibilidade da instalação de focos de $S$. mansoni no extremo sul do Brasil.

Para as considerações sobre as novas ocorrências verificadas nos dois estados, foram examinados 209 exemplares de caramujos identificados como $B$. tenagophila, $B$. peregrina e $B$. straminea, dos seguintes municípios e localidades:

\section{B. tenagophila}

- São Borja (RS), alagado próximo às margens

* Superintendência de Controle de Endemias (SUCEN) - São Paulo, SP - Brasil.

** Museu de Ciências da Pontifícia Universidade Católica do Rio Grande do Sul - Porto Alegre, RS Brasil.

Separatas/Reprints: H.M.S. Teles - Rua Paula Souza, 166 - 01027 - São Paulo, SP - Brasil.

Publicação financiada pela FAPESP. Processo Medicina $90 / 4602-1$ do arroio Barreiro, junto à estrada municipal do Barreiro (15 exemplares, coleta: abril de 1989);

- Pirapó (RS), alagado próximo às margens do rio Ijuí-Mirim, periferia da cidade (60 exemplares, coleta: abril de 1989);

- Porto Belo (SC), arroio que atravessa a estrada da marina (28 exemplares, coleta: fevereiro de 1989).

\section{B. peregrina}

- Bagé (RS), alagado próximo às margens do rio Negro, periferia da cidade, coleta: dezembro de 1989);

- Barracão (RS), arroio Marmeleiro ou Ligeiro (23 exemplares, coleta: dezembro de 1988);

- Concórdia (SC), alagado às margens do rio Jacutinga, próximo à ponte da BR-283 (dezembro de 1988).

\section{B. straminea}

- Porto Alegre (RS), aquários de uma loja de piscicultura (39 exemplares, coleta: setembro de 1989).

As espécies referidas respondem positivamente à infestação de $S$. mansoni, tanto em condições naturais ( $B$. tenagophila, $B$. straminea), como experimentais ( $B$. peregrina). $B$. tenagophila é responsável pela maior parte dos casos autóctones de esquistossomose diagnosticados no Estado de São Paulo, e pela transmissão em São Francisco do Sul (SC)(Bernardini e Machado'), foco mais meridional da doença no Brasil. Já $B$. straminea, regularmente tida como menos suscetível que $B$. glabrata e $B$. tenagophila, determina as elevadas prevalências da endemia no nordeste brasileiro. Quanto à $B$. peregrina, mesmo habilitada como transmissor de $S$. mansoni (Paraense e Corrêa) ${ }^{13}$, a propagação de $S$. mansoni pela espécie no meio ambiente não está documentada.

A propósito dos conhecimentos sobre a distribui- 
ção geográfica dessas espécies, Paraense ${ }^{9}$ apontou a colonização de $B$. tenagophila nas coleções hídricas de uma extensa área do Rio Grande do Sul, citando Capão Seco, Chuí, Curral Alto, Guaíba, Pelotas, Porto Alegre e Tramandaí. Nesta lista, Fróes e Lima ${ }^{4}$ acrescentaram Osório, Pedro Osório, Torres e Viamão. Com a descrição de Biomphalaria tenagophila guaibensis, em Arroio Grande, Capão do Leão, Guaíba, Jaguarão, Pelotas, Porto Alegre, Rio Grande e Tapes, e de B. tenagophila tenagophila em Tramandaí, Viamão (Paraense" ${ }^{\text {II }) ~ e ~ S a ̃ o ~ P e d r o ~ d o ~}$ Sul $\left(\mathrm{Vaz}^{16}\right)$, permaneceram os registros de $B$. tenagophila em Capão Seco, Chuí, Curral Alto, Tramandaí (Paraense ${ }^{9,10}$ ), Osório, Pedro Osório, Torres (Fróes e Lima ${ }^{4}$ ), Uruguaiana (Olazarri'), e agora em São Borja e Pirapó. Em trabalho subseqüente Paraense e Corrêa ${ }^{14}$ revelaram a suscetibilidade de $B$. $t$. tenagophila, o que manteve a área colonizada por hospedeiros intermediários de $S$. mansoni, a leste do Estado, praticamente inalterada. O quadro da biografia de $B$. tenagophila recebe a partir de agora modificações maiores a oeste com o reconhecimento de domínios mais amplos para a espécie.

Em Santa Catarina, B. tenagophila foi encontrada em Blumenau, Itajaí, Joinville (Paraense ${ }^{10}$ ), São Francisco do Sul (Bernardini e Machado'), e agora em Porto Belo. A presença do caramujo nesta localidade corrobora com o posicionamento firmado por Paraense ${ }^{10}$, quando propōe que a falha percebida na distribuição do planorbídeo ao sul do Município de Blumenau, deve-se à inexistência de mais coletas na área. Portanto, os indícios de que $B$. tenagophila realmente seja aí encontrada são favoráveis, pelo menos na faixa contínua ao litoral.

À luz dos conhecimentos disponíveis ${ }^{4,8.16}, B$. peregrina é espécie mais comum que $B$. tenagophila, com a ocorrência confirmada por um vasto território, ficando ausente apenas junto ao litoral de Santa Catarina. Os encontros do caramujo em novas localidades (Barracão e Concórdia) apenas integram a área de distribuição natural do caramujo. Vale a ressalva para o fato que $B$. peregrina em Barracão habitava uma poça retida da forte correnteza do arroio e acima do nível deste curso. Em função da correnteza, é factível que a colônia encontrada fosse temporária e dispersada de uma outra localidade próxima.

Apesar da presença única em Porto Alegre, $B$. straminea é uma espécie ubíqua, cuja capacidade de contaminação de aquários, represas, valas, e outras, é muito desenvolvida. Nesse Município, o planorbídeo foi reportado pela primeira vez por $\mathrm{Cu}$ nha Neto ${ }^{2}$ Em seguida foi identificado em mais localidades, em sintopia com outras espécies (DMAE) ${ }^{3}$. O encontro de $B$. straminea em aquários de uma loja de piscicultura, auxilia no esclareci- mento da forma de introdução do caramujo em novas áreas, muito provavelmente pela contaminação acidental. As informaçōes conseguidas com o proprietário do estabelecimento indicaram que diversas espécies de peixes e plantas ornamentais comercializados na cidade são importadas de produtores de São Paulo, Estado em que o caramujo exeperimentou notável expansão dos domínios territoriais nos últimos anos (Teles e $\mathrm{Vaz}^{15}$ ).

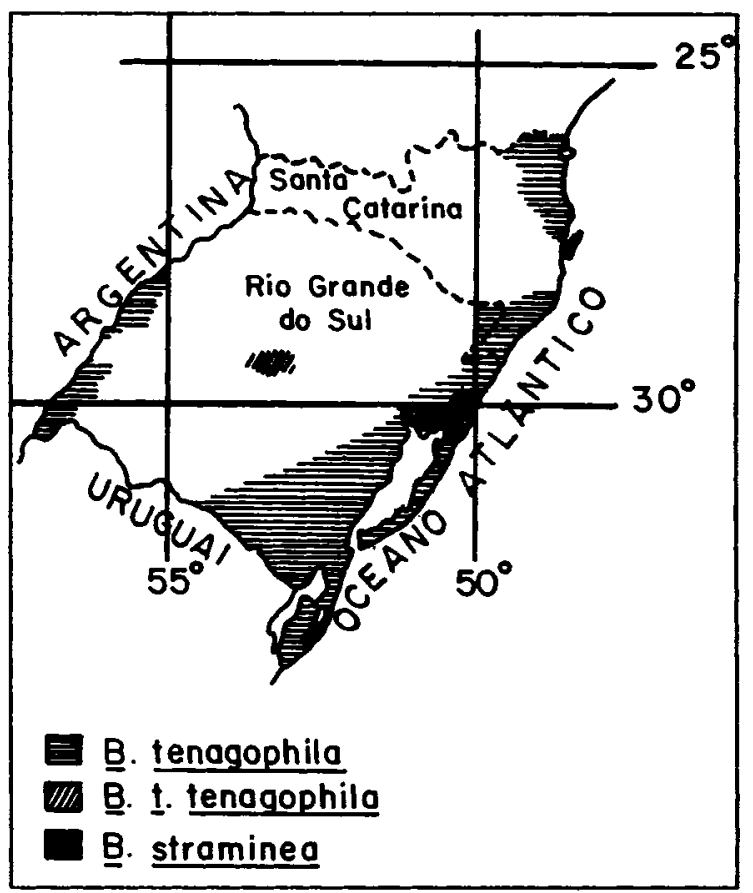

Figura- Áreas colonizadas pelas espécies de Biomphalaria hospedeiras intermediárias de S.mansoni no Rio Grande do Sul e Santa Catarina modificado de Paraense ${ }^{12}$ )

Os aspectos biogeográficos das populações dos transmissores naturais de $S$. mansoni (Figura) mostram que, em termos de extensão, a área de risco para a transmissão da esquistossome é bastante grande. Paraense e Corrêa ${ }^{14}$ adiantaram a possibilidade da expansão da doença para o sul provando a suscetibilidade de $B$. tenagophila e $B . t$. tenagophila . Também a existência da transmissão em São Francisco do Sul diz em favor desta possibilidade.

Engrossando os riscos comentados, merece destaque a existência de portadores da esquistossomose descobertos nos dois Estados ${ }^{5.6}$, inclusive com a suspeita de autoctonia no Rio Grande do Sul. Logo, as deficiências de saneamento, verificadas em todo o país, são fatores que tornam viável o ciclo do parasito na região estudada. No que tange às medidas preventivas, seria fundamental um esforço na ampliação da cobertura de 
diagnóstico, tratamento e investigação de casos humanos e o incremento dos trabalhos para o conhecimento detalhado das áreas ocupadas pelos hospedeiros intermediários de S. mansoni. Mediante este conhecimento, associando-se às áreas com maior concentração de migrantes procedentes de Estados endêmicos, ficariam sobremaneira facilitados os trabalhos de vigilância epidemiológica da endemia.

TELES, H.M.S. et al. [The distribuition of Biomphalaria (Gastropoda, Planorbidae) in Rio Grande do Sul and Santa Catarina States, Brazil]. Rev. Saúde públ. , S. Paulo, 25: 350-2 1 1991. An analysis to determine new localities colonized by the intermediate snail hosts ( $B$. straminea, $B$. tenagophila and $B$. tenagophila tenagophila) of Schistosoma mansoni from Rio Grande do Sul and Santa Catarina States (Brazil) was carried out. As regards the geographical distribuition of the schistosomiasis vector, the possible extension of the endemic disease to Southernmost Brazil is commented on.

Keywords: Biomphalaria. Residence characteristics. Schistosomiasis mansoni, epidemiology.

\section{Referências Bibliográficas}

1. BERNARDINI, O. J. \& MACHADO, M. M. Esquistossomose mansoni em Santa Catarina: isolamento do Schistosoma mansoni primeiro foco de transmissão ativa em São Francisco do Sul. Arq. catarin. Med., 10: 213, 1981.

2. CUNHA NETO, A. G. Biomphalaria straminea em Porto Alegre, Rio Grande do Sul, Brasil. Atas Soc. Biol. Rio de Janeiro. 15: 151, 1972.

3. DEPARTAMENTO MUNICIPAL DE ÁGUAS E ESGOTOS (DMAE). Ocorrência de Biomphalaria na cidade de Porto Alegre. [Apresentado ao $8^{\circ}$ Congresso Brasileiro de Engenharia Sanitária, Rio de Janeiro, 1975.]

4. FRÓES, O. M. \& LIMA, D. F. Contribuição ao estudo da biogeografia, sistemática e ecológica dos Planorbídeos (Gastropoda, - Planorbidae) do Rio Grande do Sul. Iheringia, Ser. zool., 47: 67-72, 1975.

5. LOUZADA, J. L. Z. Esquistossomose mansônica: primeiro caso autóctone do Rio Grande do Sul. Rev. bras. Med., 30: 533-5, 1973.

6. MINISTÉRIO DA SAÚDE. A SUCAM e as grandes endemias em 1987; Relatório preliminar. Brasília s. d. [Mimeografado]

7. OLAZARRI, J. Biomphalaria tenagophila (d'Orbigny) 1835 (Moll. Gastr.) en la zona de Salto Grande. $1^{\circ}$-Ambientes de cria. Comun. Soc. Malacol. Uruguay, 5: 321-46, 1981.

8. PARAENSE, W. L. The synonymy and distribuition of "Biomphalaria peregrina" in the Neotropical Region. Rev. bras. Biol., 26: 269-96, 1966.

9. PARAENSE. W. L. Fauna planorbídica do Brasil. In: Lacaz, C. da S. Brasil. São Paulo, Ed. Edgard Blücher/EDUSP, 1972. p. 213-9.

10. PARAENSE, W. L. Biomphalaria occidentalis sp. n. from South America (Mollusca Basommatophora Pulmonata). Mem. Inst. Oswaldo Cruz, Rio de Janeiro, 76: 199-211, 1981.

11. PARAENSE, W. L. Biomphalaria tenagophila guaibensis ssp. $n$. from Southern Brazil and Uruguay (Pulmonata:Planorbidae). I-Morphology. Mem. Inst. Oswaldo Cruz, Rio de Janeiro, 79: 465-9, 1984.

12. PARAENSE, W. L. Distribujção dos caramujos no Brasil. An. Acad. mineira Med.,14 (Supl.):117-28, 1986.

13. PARAENSE, W. L. \& CORRÊA, L. R. Susceptibility of Biomphalaria peregrina from Brazil and Ecuador to two strains of Schistosoma mansoni. Rev. Inst. Med. trop. S. Paulo, 15: 127-30, 1973.

14. PARAENSE, W. L. \& CORREA, L. R. Probable extension of schistosomiasis mansoni to Southern most Brazil. Mem. Inst. Oswaldo Cruz, Rio de Janeiro, 82: 577,1987.

15. TELES, H. M. S. \& VAZ, J. F. Distribuição de Biomphalaria straminea (Dunker, 1848) (Pulmonata, Planorbidae) no Estado de São Paulo, Brasil. Ciênc. e Cult., 41: 14-27, 1988.

16. VAZ, J. F. Distribuição e dispersão de Biomphalaria tenagophila (d'Orbigny, 1835) (Gastropoda, Pulmonata). Ciênc. e Cult., 41: 14-27, 1989.

Recebido para publicação em $4 / 5 / 1990$ Reapresentado em 19/6/1991 Aprovado para publicação em 1/7/1991 